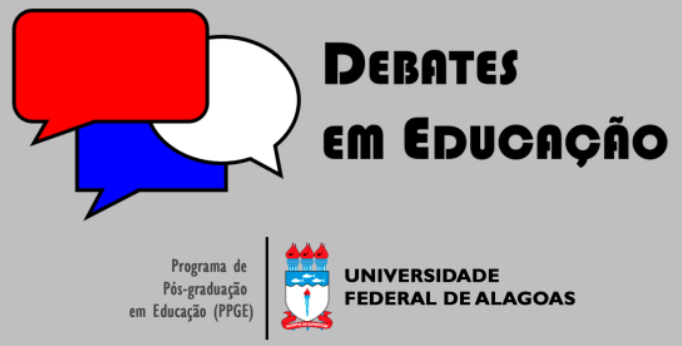

ISSN Eletrônico 2175-6600

Vol. I | No. 23 | Jan./Abr. | 2019

Yuri de Nóbrega Sales

9 i

Centro Universitário Fametro (UNIFAMETRO) yurisnobrega@yahoo.com.br

Bernadete de Lourdes Beserra 9 iD Universidade Federal do Ceará (UFC) bernadetebeserra@yahoo.com.br

\section{A PESQUISA ETNOGRÁFICA E O ENSINO DA ANTROPOLOGIA DA EDUCAÇÃO: DIÁRIOS DE CAMPO E AS SURPRESAS DA REFLEXIVIDADE}

\section{RESUMO}

Este artigo apresenta reflexões no âmbito da antropologia da educação derivadas do uso de diários de campo etnográficos, escritos pelos alunos, para a compreensão da própria sala de aula. Esta estratégia pedagógica e antropológica, utilizada entre 2015 e 2016, no curso de Pedagogia da Universidade Federal do Ceará, demonstrou a possibilidade da antropologia apresentar recursos práticos para o ofício do educadorpedagogo, sem recair na instrumentalidade. Embasado na noção de reflexividade, advinda da teoria de Pierre Bourdieu, este uso dado aos diários de campo permitiu que os discentes percebessem que a cultura é uma forma de aprendizado, ao mesmo tempo em que viviam o aprendizado formal como uma maneira de realizar a cultura.

Palavras-chave: Antropologia. Educação. Diários de Campo. Escrita Antropológica.

\section{ETHNOGRAPHIC RESEARCH AND THE ANTHROPOLOGY OF EDUCATION TEACHING: FIELD NOTES AND THE SURPRISES OF REFLEXIVITY}

\begin{abstract}
This article presents reflections on the scope of the anthropology of education derived from the use of ethnographic field journals, written by students, for the understanding of the classroom itself. This pedagogical and anthropological strategy, used between 2015 and 2016, in the Pedagogy course of the Federal University of Ceará, demonstrated the possibility of anthropology presenting practical resources for the education of the teacher-pedagogue, without falling into instrumentality. Based on Pierre Bourdieu's theory of reflexivity, this use of field diaries allowed students to perceive culture as a form of learning, while experiencing formal learning as a way of producing culture.
\end{abstract}

Keywords: Anthropology. Education. Field notes. Anthropological Writing.

Submetido em: $14 / 12 / 2018$

Aceito em: 03/04/2019

Ahead of print em: I I/04/2019

Publicado em: 25/04/2019

do: http://dx.doi.org// 0.28998/2 I 75-6600.20 I 9v I In23p375-389 


\section{A ANTROPOLOGIA DA EDUCAÇÃO ANTE O DILEMA: PROFESSOR OU ANTROPÓLOGO?}

Dentre várias possibilidades, a história da antropologia pode ser interpretada pela relação de proximidade ou distanciamento da disciplina com o seu objeto de estudo. Neste prisma, a antropologia dos primórdios da disciplina, com Malinowski, onde os nativos se mostravam sob o véu de uma realidade exótica e longínqua, apresenta-se consideravelmente distinta da antropologia urbana e da antropologia da ciência, por exemplo, estabelecidas a partir da segunda metade do século $X X$, e cujos objetos constituíam o universo cultural dos próprios pesquisadores. Este segundo momento se caracterizou pelo debruçar-se dos antropólogos sobre sua própria civilização, ato fundador do que Mariza Peirano denominou de antropologia pós-exótica (PEIRANO, 2006).

Como uma ramificação destacada do saber antropológico, a antropologia da educação também enveredou pelos desafios de uma "antropologia do mesmo". ${ }^{1}$ Da instituição escolar, que se infiltra nas memórias mais íntimas dos pesquisadores, à instituição universitária, enredada no poder, nos títulos e nos interesses dos próprios etnógrafos, os objetos de interesse investigativo situados no "quintal" dos pesquisadores se multiplicaram, ainda que sempre limitados pelas ressalvas derivadas do perigo que ronda os interessados em desvelar as regras do jogo do qual se participa (BOURDIEU, 20I3). A pesquisa sobre a formação de professores, em particular, se revelou promissora neste quesito, desvelando, ainda que timidamente, as práticas que constituem a Universidade brasileira (LAVERGNE; BESERRA, 20I2).

Porém, os antropólogos da educação rapidamente foram convidados a não apenas pesquisarem a escola, os alunos, os professores, a formação de professores, mas eles mesmos participarem, avaliarem e, às vezes, conceberem tais formações. Consequência dos lugares institucionais habituais que ocupavam e ocupam, como o de docentes em Universidades públicas, os pesquisadores-antropólogos foram convocados a se apresentarem no papel de formadores, mesmo porque é isto que afınal também são, em alguns casos, principalmente são. Não recusaram esta dupla função, advogando a similitude possível de ambas, pois seria na pesquisa etnográfica, enquanto prática de conhecimento, que residiria o recurso antropológico privilegiado para a formação docente (OLIVEIRA; NASCIMENTO; SANTOS, 20 I 4). Se não houve recusa, também não significa que inexistiram dificuldades.

Se, por um lado, o antropólogo-formador é convidado a compreender criticamente as culturas que compõem as instituições educacionais, estas mesmas que legitimam a função social do próprio

\footnotetext{
' Diferentemente de como se desenvolveu no Brasil, mais atrelado aos processos educacionais próprios dos movimentos sociais ou espaços não-escolares, inclusive porque consequente das políticas públicas decorrentes da Constituição de 1988 , o campo da antropologia da educação nos Estados Unidos sempre teve a escola e as suas questões como espaço privilegiado de pesquisa (Ver LEVINSON; POLLOCK, 20I I).
} 
pesquisador, por outro, a partir do vínculo com estas instituições, vê-se conduzido a realizar a tarefa que Ihe cabe, como docente, na composição da ordem institucional: formar profissionais, às vezes futuros professores, a partir de critérios, condições e ideais derivados das formas específicas como as políticas educacionais se concretizam nos estabelecimentos aos quais estão afiliados.

Não seria, talvez, exagero assumir que esta dupla função, que congrega aspectos muitas vezes contraditórios, perseguiu os antropólogos da educação. A questão sobre como conciliar estes saberes detentores de certas características nem sempre harmonizáveis permeou os debates da antropologia da educação no Brasil (GUSMÃO, 20 I5; ROCHA; TOSTA, 2013).

Dauster (2004), em particular, ecoando as palavras de Regina Novaes, desloca-se do plano abstrato da epistemologia e da ontologia para a dimensão dos projetos ético-políticos que sinalizam estes saberes, e sintetiza o dilema concreto que emerge do encontro entre os papéis de educador-pedagogo e o de antropólogo: "Como articular o projeto antropológico do conhecimento das diferenças com o projeto educacional de intervenção na realidade?" (p. 199). Tal dilema, de acordo com a autora, decorre do fato do pedagogo ser orientado por um "dever-ser" que é estranho ao campo antropológico (DAUSTER, $2011)$.

Como alternativa para interligar estes dois campos distintos de atuação e de conhecimento, o pensamento voltado para as "diferenças" predominou na antropologia da educação no Brasil. Ainda que permanecesse a tensão entre o sentido dado às "diferenças" culturais produzidas/desveladas, por exercício de comparação, no âmbito do conhecimento antropológico e o sentido do termo "diversidade", tematizado pelas diretrizes normativas e pelas políticas públicas educacionais orientadas por uma perspectiva multiculturalista, foi esta equiparação entre essas noções que unificou a antropologia e a educação no que concerne à formação docente.

A diferença, no campo antropológico, e a diversidade, na seara das políticas educacionais, extrapolando suas reais semelhanças, se apresentam como pontes de interlocução entre a antropologia e a educação. Elas permitem o pareamento entre o antropólogo, em sua tarefa de estranhar o que lhe é familiar e familiarizar-se com o que lhe é estranho, e o professor atônito diante da miríade de culturas, personificadas em seus diferentes alunos, dispostos numa sala de aula destinada ao aprendizado. Em ambos os casos, uma atitude de relativização metodologicamente guiada se apresentaria como a operação adequada para o contato com a alteridade. Assim, imagina-se, o docente seria capaz de enxergar e compreender as diferenças, por meio dos instrumentos conceituais e atitudinais aprendidos com a antropologia, e criar linhas de ação, a partir da expertise adquirida no campo pedagógico, para atuar no campo do aprendizado e da socialização educacionais direcionados à diversidade.

Porém, existem outras possibilidades de exercer e desenvolver a antropologia da educação que, se não ignoram ou negam o papel das diferenças nos contextos educacionais, não se restringem ao escopo 
do manejo, da inclusão ou da convivência com os "diferentes". Como afirma Álamo Pimentel (20।4) sobre o uso da etnografia em contextos de educação formal, a partir de um enquadre antropológico:

A etnografia como processo de produção de conhecimento que tem como premissa o exercício da alteridade, oferece importantes alternativas ao questionamento das práticas de ensino naturalizadas nos cotidianos escolares e, de certa forma, pode consolidar posições políticas de descolonização dos processos de ensino, à medida que faz-nos aprender outras formas de ensinar e conviver com as heterogeneidades sociais e culturais na sala de aula (p. 50).

É por este ângulo, que apesar de pouco abordado também integra a Antropologia da Educação, o da descolonização dos processos de ensino e da criação de outras formas de ensinar, que este artigo se orienta. A experiência formativa a ser apresentada, ocorrida entre os anos de 2015 e 2016 na disciplina "Antropologia da Educação", ofertada no curso de Pedagogia da Universidade Federal do Ceará, apresenta o uso programático de diários de campo etnográficos direcionados à pesquisa da própria disciplina, em especial a "sala de aula" e suas múltiplas ramificações institucionais. ${ }^{2}$

Num exercício que se ampara na reflexividade apontada por Bourdieu (BOURDIEU; WACQUANT, 1992) o uso de diários de campo para investigar as aulas - é importante ressaltar, nas quais eram ministradas as orientações teóricas e práticas necessárias ao próprio manejo dos diários de campo pretendeu usar a antropologia/sociologia como ferramenta de auto-socioanálise, no intuito de facilitar o domínio reflexivo sobre o próprio habitus coligado ao campo educacional, tanto por parte dos docentes (professora e monitores) quanto dos discentes.

O uso do diário de campo neste enquadre se apresentou como uma estratégia simultaneamente pedagógica e antropológica que operou em diferentes níveis, todos articulados à referida disciplina, que podem ser condensados em três movimentos reflexivos em direção à investigação da cultura e das instituições escolares dos próprios docentes e discentes: I) pesquisar a instituição universitária à qual os docentes e discentes estavam filiados: aqui o "mesmo" se apresenta na figura da instituição; II) pesquisar os sujeitos, o contexto e as estratégias educacionais envolvidas no processo pedagógico de aprender a pesquisa etnográfica e as atitudes antropológicas da relativização: o "mesmo" se apresenta na figura da sala de aula, com todos os seus elementos derivados; III) pesquisar as maneiras, as peculiaridades e os obstáculos presentes na aprendizagem ocorrida em sala de aula: o "mesmo" se mostra na figura dos próprios discentes e seus processos intra e interpessoais de cognição.

\footnotetext{
${ }^{2}$ Como se explicará mais detalhadamente adiante, a utilização de diários de campo como instrumento para um aprendizado "prático" da antropologia, ou para uma antropologia da educação, foi uma estratégia do projeto de iniciação à docência "A Construção do Olhar Antropológico na Formação Docente", iniciado em fevereiro de 2013 (ver BESERRA, 20I6a). Nesta primeira versão, o foco da observação não era apenas a sala de aula, mas aqueles espaços da unidade acadêmica que chamavam a atenção dos alunos e os inspiravam a elaborarem questões para a "pesquisa etnográfica" que desenvolveriam ao longo da disciplina. $\bigcirc$ foco apenas na sala de aula foi uma consequência da repressão que o projeto passou a sofrer após a publicação de artigo (BESERRA; OLIVEIRA; SANTOS, 20।4) que chamou a atenção para problemas da instituição que questionavam o seu discurso público. Os efeitos deste redimensionamento, porém, longe de evitar a reflexão sobre a instituição universitária, fizeram com que esta retornasse, pela via dos próprios alunos, associada à pesquisa sobre a sala de aula.
} 
É importante mencionar que os citados movimentos de reflexividade não foram estabelecidos a priori, mas observados e formulados a partir da interação entre discentes e docente no decorrer da disciplina de "Antropologia da Educação" (2015-2016) e mediada pelo uso dos diários de campo para o estudo do próprio contexto educacional. Deste modo, os três processos elencados são produtos não tanto de um projeto intelectual particular, seja de um indivíduo ou de um grupo, mas principalmente a descoberta processual e conjunta de como, pela reflexividade, tornar visível, nos modos de aprender/ensinar tanto quanto nos conteúdos a ser aprendidos/ensinados nas aulas de antropologia da educação, a complexidade das forças sociais envolvidas em qualquer ação educativa. Afinal, não há nada menos neutro do que o processo de ensino e aprendizagem (BESERRA; LAVERGNE, 20।6).

Por fim, trata-se de expor neste artigo uma tentativa limitada e pontual de refletir, a partir de um determinado uso dado aos diários de campo na educação, o dilema apontado por Dauster. $\bigcirc$ intento é articular, de dentro do campo e do ofício da pedagogia, nos quais se situavam os estudantes da referida disciplina, o senso crítico e reflexivo da antropologia com o projeto de mudar a realidade, próprio da educação.

Portanto, a experiência que será apresentada não se pretende um modelo de antropologia da educação, que poderia ou deveria ser reproduzido em outros contextos, mas uma contribuição empírica e teórica de um projeto mais amplo e complexo, o de pensar e realizar "[...] uma antropologia [da educação] que não se restringe à indagação sobre as questões mais aparentes relativas à diversidade" (BESERRA; LAVERGNE, 20।6, p. 88).

\section{O CONTEXTO QUE ANTECEDE O USO DO DIÁRIO DE CAMPO DIRECIONADO AO PRÓPRIO PROCESSO DE APRENDIZAGEM}

O uso dos diários de campo voltado para a descrição da disciplina "Antropologia da Educação" é decorrência de um conjunto de experiências docentes, de resultados de pesquisas e das elaborações conceituais desenvolvidos pela autora deste artigo, que será denominada nesta seção de "professora/pesquisadora", em sua trajetória neste campo do conhecimento (ver BESERRA, 20।6b). Para permitir a contextualização e, assim, a melhor compreensão deste experimento, faz-se necessário pontuar algumas das ideias e práticas que antecedem este uso dos diários de campo, reproduzindo, sinteticamente, dados que estão dispersos em diversos textos já publicados.

Já em 2006, a professora/pesquisadora (ver BESERRA; LAVERGNE, 20I2) explicitava o seu posicionamento sobre a centralidade da reflexividade nas disciplinas de sociologia e antropologia voltadas aos cursos de licenciatura, demarcando, na ocasião, seu objetivo de facilitar a reflexão dos estudantes sobre 
suas trajetórias existenciais até a entrada na Universidade, no intuito de se aperceberem dos fatores sociais envolvidos nestes percursos biográficos. Tratava-se de utilizar a sociologia como um "esporte de combate" (BOURDIEU, 1983) na própria disciplina, e não apenas como conteúdo intelectual da disciplina. O objetivo era realizar a verdadeira função desta compreensão sociológica, a de ser um instrumento para os discentes se perceberem nas tramas do campo social e simbólico ao qual pertencem (BESERRA; LAVERGNE, 20 I2).

Também já se fazia presente, fruto de suas experiências na docência, a percepção de que a bandeira do "respeito à diversidade" era apropriada pela cultura institucional - em específico, neste caso, a estudantil - e convertida num ambiente acadêmico em que a distinção entre opinião e conhecimento científico se enfraquecia, legitimando, explícita ou tacitamente, uma cultura da ignorância. $\bigcirc$ efeito destes pressupostos provocaria o descarte da função de instruir própria da docência, a partir da qual se deduz certo dever de "correção" do pensamento e da prática discente. A utopia de fundo no discurso dos discentes era a criação de um ambiente educacional em que as relações e os rituais de poder fossem artificialmente extirpados da realidade social. Fazia-se evidente, portanto, a necessidade de pensar e lidar com a "diferença" de um modo que não levasse ao resultado ilusório da horizontalidade de poder nas instituições (BESERRA; LAVERGNE, 2012).

Posteriormente, comprovou-se o que já se afigurava como hipótese: que a cultura de legitimação da ignorância não era restrita aos discentes, mas se imbricava com as atitudes e pensamentos dos docentes da instituição universitária investigada pela professora/pesquisadora, e que estes, na verdade, nunca pretenderam, de fato, abolir as relações de poder, mas as travestiam como parte de uma estratégia de "populismo docente" (BESERRA; OLIVEIRA; SANTOS, 20।4).

É por este período que a professora/pesquisadora passa a utilizar os diários de campo para investigar a própria instituição universitária a qual estava filiada, impulsionada pelos interesses e curiosidade dos estudantes desta mesma universidade. Diversos acontecimentos, antes naturalizados, se tornavam, por meio do estranhamento gerado a partir das descrições etnográficas desenvolvidas na disciplina, objeto de reflexão. Por exemplo, as formas e o intuito das avaliações nas disciplinas, bem como a flexibilização dos horários desta; a centralidade da "cantina" para o funcionamento da faculdade investigada; o valor reduzido ou inexistente dado ao exercício da escrita na formação dos profissionais da pedagogia (BESERRA; OLIVEIRA; SANTOS, 2014).

Se, por um lado, o então recente direcionamento dos diários de campo para a descrição e compreensão da própria instituição de ensino supria necessidades mais pragmáticas - afinal, os estudantes não poderiam alegar dificuldades de gestão do tempo e nem obstáculos de locomoção para chegar ao "campo" -, esta não era a justificativa principal. A proposta se revestia do entendimento de que não seria possível dissociar a prática pedagógica das instituições nas quais ela é reproduzida, legitimada e ensinada. 
Posteriormente, o diário de campo como instrumento de descrição e coleta de dados foi direcionado à investigação da disciplina "Antropologia da Educação". A partir de 2013, com a aprovação do projeto de iniciação à docência A Construção do Olhar Antropológico na Formação Docente, iniciado em fevereiro do mesmo ano, a sala de aula se torna objeto de observação, mas apenas dos monitores. Estes possuíam, dentre outras, a função de descrever em seus diários de campo, a partir de observações etnográficas, situações, comportamentos, atitudes, discursos e qualquer outro fenômeno que se relacionasse à prática docente, sobretudo os seus efeitos mais superficiais sobre os discentes. Nas avaliações quinzenais, realizadas apenas com a equipe docente (monitores e professora), eram compartilhados excertos dos diários de campo e elaboradas reflexões sobre padrões e expressões culturais evidentes no processo de ensino e aprendizado que marca a sala de aula.

O objetivo, porém, não se direcionava tanto à compreensão abstrata da dinâmica social e cultural da sala de aula, mas à viabilidade de aprimorar a prática docente, em especial as situações nas quais se apresentavam dificuldades de comunicação entre a professora e os alunos (BESERRA, 20 I 6a). O diário de campo surgia como um espelho do habitus da professora/pesquisadora, que revelava suas implicações em certas disposições e lugares, antes inconscientes, do campo educacional e universitário brasileiro. No caso dos monitores, não apenas aprendiam a realizar as descrições etnográficas sobre práticas e situações pedagógicas, como desenvolviam nas referidas reuniões, por associação, reflexões sobre suas próprias práticas docentes.

A partir de 2015, o uso do diário de campo para a reflexão das práticas docentes relacionadas à sala de aula não apenas se manteve como tarefa sistemática, mas fora incluída como atividade obrigatória para todos os discentes. Deste modo, o roteiro semanal das aulas foi estabelecido para permitir um momento específico para a elaboração dos diários de campo, com descrições sobre acontecimentos e situações pertinentes ocorridos em sala de aula, e um momento para o compartilhamento das percepções registradas nos diários de campo e a elaboração conjunta de reflexões derivadas destas percepções.

Assim, a aula tinha início com a leitura de trechos dos diários de campo, elaborados na semana anterior, que se mostravam na percepção de algum discente ou da própria professora importantes ou elucidativos daquela cultura do dar/assistir aula. A docente recebia com frequência os diários de campo dos alunos, os quais lia, no intuito de avaliar individualmente o grau de compreensão e absorção dos conceitos na prática da observação cultural. Estando de posse destes escritos, portanto, a professora também poderia selecionar trechos que considerava importante compartilhar com toda a classe. Após esta etapa, transcorria a aula, em seu conteúdo programático estabelecido pela ementa da disciplina. Por fim, eram reservados cerca de 15 minutos, ao final da aula, para que os estudantes descrevessem em seus diários de campo as percepções e experiências ocorridas no dia, que seria o material com o qual se iniciaria a aula da semana seguinte. 
Este movimento de inflexão que direcionou o diário de campo para a investigação sistemática, por parte dos discentes, da própria disciplina, apesar de aparentemente simples, produziu efeitos pedagógicos e teóricos marcadamente relevantes. Nesta nova configuração, o diário de campo deixa de ser um instrumento pedagógico, utilizado para alcançar um objetivo especifico e pontual, como ocorria quando realizado por monitores, para se tornar uma estratégia, mais ampla e complexa, derivada de uma didática antropológica (BESERRA, 20I5; SILVA JR, 20।6; MARTINS, 20।7). É esta transformação que justifica o enfoque dado, na seção seguinte, às consequências práticas e teóricas do uso do diário de campo para a investigação do próprio processo educacional, realizado na disciplina "Antropologia da Educação".

\section{DOS DIÁRIOS E DAS SUAS CONSEQUÊNCIAS}

Entre 2015 e 2016, os estudantes matriculados na disciplina "Antropologia da Educação", demonstraram surpresa diante da proposta de usar os diários de campo com o intuito de compreender, etnograficamente, os processos culturais e educacionais que se apresentavam na própria disciplina. Curiosamente, a mesma intensidade associada à surpresa revelada pelos discentes no início do semestre podia ser reencontrada ao final do período letivo na maioria dos alunos, agora vinculada à satisfação com os aprendizados realizados durante o semestre. $\bigcirc$ que ocorreu entre a surpresa e a satisfação? $\bigcirc$ que os estudantes aprenderam neste percurso? Estas são indagações pertinentes para compreender a singularidade deste tipo de uso dos diários de campo no ensino de antropologia.

Incluir a realização dos diários de campo como tarefa constituinte da estrutura da aula, com os horários iniciais e finais reservados para este exercício, fez com que os estudantes ampliassem sua atenção e se voltassem ao ambiente e às interações próprias da ritualística do dar/assistir aula (BESERRA; LAVERGNE, 2016). Dos conteúdos, em si, aos mínimos detalhes ambientais e interacionais, a miríade de acontecimentos que constituem a dinâmica cultural e educacional de uma sala de aula tornava-se, aos poucos, explícita e visível. Eles aprendiam, portanto, com a escrita dos diários de campo e as reflexões desenvolvidas a partir destes, que os pequenos atos cotidianos sempre estão, em algum grau, vinculados com realidades sociais mais amplas e complexas, e as revelam.

Juntamente com o aprendizado do estar atento e da descoberta dos significados sociais e culturais presentes numa sala de aula, os discentes se implicavam, com curiosidade, num processo de descoberta da realidade educacional. No geral, se mostrava mais potente e mais sedutor aos estudantes o desafio de investigar aquilo antes considerado um tabu, uma "caixa preta", a sala de aula, do que compreender o exótico que reside fora do seu cotidiano, como uma etnia indígena. Mobilizados pelo convite da professora da disciplina para enxergar o que está escondido "atrás da porta", surgia a disponibilidade para a reflexão e 
o estudo, atitudes essenciais para que a escrita dos diários de campo não se tornasse apenas um ato mais ou menos mecânico de descrição, mas um instrumento de compreensão da realidade.

Todos estes fatores levaram os estudantes a compreenderem, por meio das descrições, indagações e reflexões que realizavam em suas pesquisas sobre a sala de aula, a atitude antropológica da relativização cultural. A sala de aula, antes naturalizada e banalizada, se tornava estranha, incompreensível, confusa e misteriosa. Esta travessia em direção ao conhecimento, uma vez iniciada, impulsionava os estudantes a tornarem a sala de aula familiar novamente, mas agora com outra compreensão das forças sociais que a constituem.

O uso dos diários de campo para o entendimento da própria sala de aula, porém, não se destacou apenas por fazer coincidir o aprendizado das atitudes antropológicas vinculadas à relativização cultural com o ambiente mais relevante à prática pedagógica profissional, a sala de aula. Se assim fosse, levaria ao mesmo resultado os discentes realizarem, individualmente, pesquisas etnográficas relativas a outros espaços, ou mesmo disciplinas, e compartilharem as percepções e os resultados na aula de "Antropologia da Educação".

O debruçar-se, por meio dos diários de campo, sobre a própria experiência educacional concreta e atual, a sala de aula de "Antropologia da Educação", criou as condições sociais propícias para o aprendizado, já que este, de acordo com Jean Lave (1988), é um processo contínuo e baseado em experiências de participação na vida cotidiana. As relações de continuidade entre momentos de uma aula (comentários sobre os diários, no início, e a escrita dos diários, ao final) e entre momentos de diferentes aulas (os diários realizados ao final de uma aula são comentados no início da próxima) permitem costurar um movimento ininterrupto de aprendizado, durante todo o semestre, que evita a dispersão dos estudantes.

Além disso, o discente não apenas investiga aquilo que compõe a sua vida cotidiana - a "sua" sala de aula - mas também participa, verdadeiramente, deste processo. As reflexões derivadas dos diários de campo produzidos pelos estudantes não raro levam a mudanças concretas, sejam sutis ou evidentes, na dinâmica da sala de aula, modificando alguma atitude docente, algum aspecto da relação entre os discentes, certas referências bibliográficas adotadas, a organização temporal das atividades em sala de aula e tantas outras possibilidades. Os estudantes percebem que seus esforços intelectuais e sensíveis transformam e aperfeiçoam as aulas das quais participam, e acompanham como isso acontece.

Assim, eles aprendem, por "incorporação" mais do que por análise cognitiva, as relações entre as percepções culturais derivadas da auto-socioanálise que os diários de campo proporcionam e os efeitos pedagógicos destas na dinâmica da sala de aula; ou seja, participam de um processo contínuo e vivenciado que relaciona, nas duas direções, a auto-percepção cultural e a transformação pedagógica. Evidentemente, este processo complexo não ocorre na dimensão individual, o que leva a outra consequência do uso dos 
diários de campo voltados à auto-compreensão da disciplina: cria-se uma "comunidade de prática" (LAVE;WENGER, 199I).

Todos os integrantes da disciplina estão imersos num mesmo processo compartilhado de reflexão e transformação dos aspectos culturais e pedagógicos vinculados com a sala de aula de "Antropologia da Educação". Neste sentido, é uma comunidade. E todos não apenas compartilham um ofício almejado, o de educador, mas praticam este ofício, indiretamente, no momento em que participam da conversão das percepções culturais em "correções" do percurso pedagógico. Neste momento, a sala de aula se torna um "lugar de deslocamento intelectual no qual podemos descobrir outras formas de produzir conhecimento em regime de cofuncionamento com presenças que constituem conosco este espaço de relação" (PIMENTEL, 2014, p. 52).

É perceptível a composição de uma comunidade, na qual se compartilha uma mesma experiência de aprendizado, ainda que singularizada pelas histórias de vida e as posições distintas no campo educacional que cada um ocupa, na medida em que não há assimetria rígida de poder: todos ocupam, em diferentes momentos e em distintas situações, tanto a posição de objeto quanto a de sujeito. Isso inclui, claro, também a docente.

A observação da sala de aula, realizada pelos estudantes, abrange em seu espectro os gestos, as ações, as expressões faciais, o discurso e outros elementos constitutivos da prática docente e da pessoa que a realiza. Neste sentido, o professor ocupa uma posição de objeto diante do olhar antropológico dos discentes, que muitas vezes compartilham, no início da aula, as percepções geradas por este olhar.

Assim, as posições de poder se tornam mais complexas quando se usa o diário de campo para compreender a própria sala de aula. Se os estudantes ocupam, muitas vezes, uma posição na relação pedagógica que os aproxima do lugar de objeto, no sentido de se apresentarem como "alvos" de reflexões e avaliações realizadas por um "outro" (por exemplo, nas avaliações institucionais da disciplina, que condicionam ou não a sua aprovação), também se aproximam, em outras situações, da posição de sujeito (quando descrevem ou refletem, nos diários de campo, sobre certas atitudes do docente). $\bigcirc$ mesmo ocorre com o professor: seu lugar habitual de sujeito é, em diversas situações, substituído pelo de objeto, quando enxerga a si através do olhar do estudante sobre sua prática docente.

Este intercâmbio de papéis torna as relações de poder mais explícitas e, consequentemente, mais próximas à reflexão, sem que se apele a uma ilusória horizontalidade de poder na relação entre discentes e docentes. Assim, o olhar antropológico voltado para a própria sala de aula constrói uma dinâmica de distribuição balanceada das relações de força, a partir de permutas pontuais de papéis, o que possibilita a existência e a expressão da "diferença" no interior do campo de poder que constitui a educação escolar.

Esta estratégia para lidar com as relações de força na sala de aula, implícita nesse modelo de uso dos diários de campo, não decorre apenas da impossibilidade efetiva de abolição do poder nas relações 
entre docente e discentes. O poder não é apenas um obstáculo aos objetivos pedagógicos e, portanto, necessita ser manejado pela ausência de alternativas. As relações de poder entre docente e discentes presentificam outras forças sociais mais amplas, e ao fazer isso, se tornam vias potenciais para o desvelamento reflexivo destas.

É por isso que a escrita dos diários de campo voltada para a própria sala de aula revelou aos discentes a presença de uma "ausência ativa" nos processos de ensino e aprendizagem: a instituição escolar. Ausência, porque invisível, naturalizada; ativa, já que participa, de uma modo ou outro, de todos os processos pedagógicos e culturais que ocorrem no interior da sala de aula. De resto, não apenas os discentes não se atentavam para a importância da instituição escolar nas interações culturais que constituem a disciplina. Também a antropologia da educação, quando voltada à reflexão sobre a formação de professores e a relação destes com a "diferença", tende a focar mais nos déficits individuais (do professor e do aluno) do que no papel das instituições escolares em moldar ou conduzir as relações de ensino e aprendizagem (BESERRA; LAVERGNE, 20I2).

Com o uso dos diários de campo, porém, os estudantes aos poucos foram percebendo a relação direta entre o aprendizado de ser docente, vivenciado no espaço da sala de aula, e a dinâmica institucional da universidade, composta por hábitos, relações de poder, currículos ocultos, transações políticas que ultrapassam o espaço físico escolar etc. Inicialmente tomada como um ambiente neutro de aprendizado, a sala de aula passou a ser vista como uma extensão da instituição escolar, evidenciando a ligação intrínseca entre ambas.

Isso significou o aprendizado de que não há uma separação absoluta entre o "dentro" e o "fora" da sala de aula. A partir do aprendizado do olhar antropológico voltado para o próprio contexto educacional, os estudantes descobrem, por diferentes maneiras e em graus distintos, que a instituição escolar já está "dentro" da sala de aula, encarnada, por exemplo, na figura do professor e seu papel de poder. Ao contrário do que um olhar apressado poderia julgar, esta percepção não rompe as relações educacionais próprias à sala de aula, mas as intensifica e ressignifica.

Se, por um lado, os estudantes se descobrem, na vivência reflexiva na e sobre a sala de aula, como parte de uma configuração institucional escolar que thes surge como alheia, porque interpretada inicialmente como "distante" das atividades pedagógicas relacionadas à disciplina, por outro percebem que a sala de aula possui o potencial de modificar esta configuração. A via é, necessariamente, de mão dupla. Isso porque a instituição escolar é um espaço polissêmico, e, assim, sujeita às disputas em torno de seus significados e configurações sociais (OLIVEIRA, 20।4)

Tal aprendizado se dá, de fato, por meio do olhar antropológico voltado à própria sala de aula: é voltando-se para si, como estudante numa sala de aula concreta, que se desvela a escola como um Outro, 
para que se possa, então, redescobri-la, como parte da vida cotidiana desnaturalizada, determinável e determinante. Como descreve Beserra (20।5), a partir de sua experiência docente:

Logo começaram a desnaturalizar aquele cotidiano e identificar o que achavam problemático. $O$ mau-atendimento dos funcionários, das secretarias, os problemas de manutenção e limpeza das salas de aula e banheiros; atrasos dos professores e problemas de avaliação pareciam ser, todos, algo a ser resolvido no âmbito da administração [...] Aos poucos, outros temas foram surgindo. Alguns queriam refletir sobre a docência: os professores que defendem uma 'pedagogia' e praticam outra e vários outros temas relacionados à formação do professor (p. 5)

Deste modo, a sala de aula, a relação docente-discentes e a instituição escolar se apresentam como dimensões imbricadas na reflexividade, conduzida pelos diários de campo, do futuro educador sobre o contexto educacional, social e cultural que configuram certos papéis, e não outros, que este ocupa na sociedade.

\section{O QUE OS DIÁRIOS DE CAMPO SOBRE A SALA DE AULA PODEM ENSINAR À ANTROPOLOGIA DA EDUCAÇÃO}

Estudantes de licenciatura em Pedagogia, mesmo imersos no processo de tornarem-se docentes, tendem a perceber a disciplina de antropologia da educação como "sem propósito", já que esta não os ensina "a fazer" (ROSISTOLATO; PRADO, 20I 5, p. 99); ou seja, não ensina uma prática articulada com o ofício do pedagogo. Esta percepção, enraizada na vivência empírica dos estudantes, traz de volta o dilema posto por Dauster (2004) em termos mais teóricos: como conciliar o conhecimento das diferenças com o projeto de mudar a realidade? Como unir a antropologia e a educação?

Percebe-se que entre estes dois saberes geralmente se constitui uma relação de assimetria, tendo a antropologia (seus pressupostos, interesses, valores) primazia sobre a educação. Como afirma, Taddei e Gamboggi (20|6):

\footnotetext{
Nosso ponto de partida é a constatação de que a relação entre a antropologia e a educação, enquanto campos acadêmicos, tem sido marcada por uma acentuada assimetria. A própria expressão antropologia da educação, por exemplo, ilustra esse fato. A antropologia é aí evocada para esclarecer o que é a educação, ou pelo menos o que são suas práticas institucionalizadas, como a escola, e quais implicações elas têm para a vida coletiva. (p. 29)
}

Esta assimetria, enquanto existir, impossibilita uma clara definição sobre o dilema que versa sobre a conciliação da antropologia com a educação. Respostas mais pontuais e individualizadas na figura do professor-antropólogo, como a familiarização efetiva com o campo da pedagogia (OLIVEIRA; NASCIMENTO; SANTOS, 20 I4), ainda que bem-vindas e louváveis, não parecem ser suficientes. É neste sentido que os diários de campo voltados para a compreensão da própria aula que o professor- 
antropólogo ministra parecem oferecer pistas pertinentes para a conjugação, na prática da formação de professores, da antropologia com a educação.

Parece-nos que o que de melhor a antropologia pode realizar com o educador (e não para o educador), na sua formação docente, é o aprendizado de ler a ação pedagógica a partir do campo cultural e institucional mais amplo que Ihe constitui, ao mesmo tempo que oferecer ferramentas para o docente reconhecer que intervir e lidar com estes campos se apresenta, também, como uma ação pedagógica. Isso só pode ocorrer se o estudante aprender, na prática, a pensar reflexivamente a educação, pois ele, futuro educador, será simultaneamente o produto e o potencial transformador destes campos que lhe antecedem.

O singelo ato de flexionar o olhar sobre a própria sala de aula, provocado por este uso aqui referido dos diários de campo, permite que os futuros docentes, por um lado, aprendam antropologia a partir da pedagogia, já que é através da observação de padrões e traços culturais próprios do contexto de ensino/aprendizado que se interioriza o olhar antropológico, e, por outro, ainda mais raro de ocorrer, que haja o aprendizado da pedagogia por meio da antropologia, já que o estudante compreende o campo educacional, e o projeto de mudar a realidade daí derivado, como cultura do aprendizado, materializada na interseção entre a instituição escolar e o fazer educativo da sala de aula. No primeiro caso, o estudante percebe que cultura é uma forma de aprendizado, enquanto, no segundo, como se produz aprendizado como uma forma de realizar cultura. Assim, não apenas a cultura e o aprendizado se mostram integrados, mas também os atos da percepção e da produção, característicos dos projetos, respectivamente, antropológico e pedagógico, se complementam. Neste sentido, há um movimento contínuo que leva da antropologia à educação e vice-versa.

Pode-se concluir que, nestas condições, os estudantes não aprendem propriamente uma antropologia aplicada à educação, e nem mesmo uma antropologia aplicada à formação docente. Eles tomam conhecimento, a partir do uso dos diários de campo, de uma didática antropológica (BESERRA, 2016a) que se relaciona com a prática docente sem se apresentar como um saber instrumental (GUSMÃO, 20I0). Trata-se, assim, de uma prática direcionada a Ihes auxiliar, pela via da reflexividade, no seu futuro ofício de educador.

\section{REFERÊNCIAS}

BESERRA, Bernadete. A construção do olhar antropológico na formação docente. Coleção Textos FCC (Impresso), v.50, p.93 - 121, 2016a.

BESERRA, Bernadete. Dos riscos da diferença: etnografia de um percurso acadêmico. Fortaleza: Edições UFC, $2016 \mathrm{~b}$. 
BESERRA, Bernadete. Da antropologia da educação a uma didática antropológica. In: REUNIÃO EQUATORIAL DE ANTROPOLOGIA, 5.; REUNIÃO DE ANTROPÓLOGOS DO NORTE E NORDESTE, 14., 20I5, Maceió. Anais... Maceió: Edufal, 2015.

BESERRA, Bernadete; LAVERGNE, Rémi. Heroína ou vilã? Notas sobre uma experiência de ensino de Sociologia da Educação. In: CHAGAS, Eduardo et al (Orgs.). Indivíduo e Educação na Crise do Capitalismo. Fortaleza: Edições UFC, 2012.

BESERRA, Bernadete; OLIVEIRA, Leiry; SANTOS, Carolina. Entre o populismo docente e o dom da fala discente: problemas do ensino básico que sobrevivem à formação superior em pedagogia. Revista

Dialectus, ano 2, n. 5, p. I50-165, ago./dez. 20|4, p. 462-481.

BESERRA, Bernadete; LAVERGNE, Rémi. Etnografando a sala de aula: contribuições da antropologia à formação de professores. Revista Anthropologicas, v. 27, n. I, p. 72-101, 2016.

BOURDIEU, Pierre. Questões de Sociologia. Trad. Jeni Vaitsman. Rio de Janeiro: Marco Zero, 1983.

BOURDIEU, Pierre. Homo Academicus. Florianópolis: Ed. da UFSC, 2013 [1 984$].$

BOURDIEU, Pierre \& WACQUANT, Loic. An invitation to reflexive sociology. Chicago: Chicago University Press, 1992.

DAUSTER, Tania. "Entre a Antropologia e a Educação": a produção de um conhecimento imprescindível e de um conhecimento híbrido. ILHA: Revista de Antropologia, v. 6, n. I-2, p. 197-207, 2004.

DAUSTER, Tania. Etnografia, modo de conhecer: entre a Antropologia e a Educação. Educação on-Line (PUCRJ), v. 9, p. 10-15, 201।.

GUSMÃO, Neusa. Por uma antropologia da educação no Brasil. Pro-posições: Revista da Faculdade de Educação/UNICAMP, v. 21 , n. I, p. 259-265, maio/ago. 2010.

GUSMÃO, Neusa. Antropologia e educação: um campo e muitos caminhos. Linhas Críticas, v. 2 I , n. 44, p. 19-37, jan./abr. 2015.

LAVE, J.; WENGER, E. Situated learning: legitimate peripheral participation. Cambridge: Cambridge University Press, 1991.

LAVERGNE, R.; BESERRA, Bernadete. Exercício para a construção de uma antropologia do ensino superior In: XV ENCONTRO DE CIÊNCIAS SOCIAIS DO NORTE E NORDESTE, 20I2, Teresina. Anais... Disponível: http://www.sinteseeventos.com.br/ciso/anaisxvciso/resumos/GTI I -02.pdf

LEVINSON, B.; POLLOCK, M. A Companion to the Anthropology of Education. Malden, MA: WileyBlackwell. $201 \mathrm{l}$.

MARTINS, Isayanne. Antropologia da Educação na formação de professores: um estudo etnográfico. Dissertação (Educação) - Universidade Federal do Ceará, 2017.

OLIVEIRA, Amurabi. Antropologia, colonialidade e pós-colonialidade: diálogos possíveis com a educação. Quaestio, v. 16, n. I, maio 2014, p. II-23, 2014.

OLIVEIRA, Amurabi; NASCIMENTO, Fernanda; SANTOS, Jhones. $O$ ensino e seus espelhos: a formação antropológica para não antropólogos. Cadernos de Pedagogia, ano 7, v. 7, n. |4, p. | |4- |25, jan./jun. 2014. 
PEIRANO, Mariza. A teoria vivida: e outros ensaios de antropologia. Rio de Janeiro: Jorge Zahar, 2006.

PIMENTEL, Álamo. A atitude etnográfica na sala de aula: descolonizando os processos de ensino.

REALIS, v. 4, n. 2, p. 49-7I, jul./dez. 2014.

ROCHA, Gilmar; TOSTA, Sandra. Antropologia e Educação. Belo Horizonte: Autêntica, 2013.

ROSISTOLATO, Rodrigo; PRADO, Ana. O lugar da antropologia na formação de educadores. Revista Café com Sociologia, v. 4, n. 2, p. 98-। II, 2015.

SILVA JÚNIOR, Silvio Roberto Dias da. A dádiva do outsider: a didática antropológica aplicada à formação de professores. Dissertação (mestrado) - Universidade Federal do Ceará, Fortaleza, 2017.

TADDEI, Renzo; GAMBOGGI, Ana. Educação, antropologia, ontologias. Educação e Pesquisa, v. 42, n. I, p. 27-38, jan./mar. 2016. 